\title{
O ESPAÇO METROPOLITANO NO BRASIL: nova ordem espacial?
}

\author{
Luciana Teixeira de Andrade*
}

\begin{abstract}
O texto tem como objetivo principal analisar as recentes mudanças na ordem espacial das regiões metropolitanas brasileiras e, em particular, na Região Metropolitana de Belo Horizonte. Inicia-se com um diálogo com a literatura internacional sobre o tema, para, em seguida, mostrar os debates nacionais. Tem, como referente empírico, uma série de estudos e índices construídos a partir dos resultados do Censo Demográfico de 2010. Mostra como o modelo dual centro versus periferia é limitado para a compreensão da atual ordem socioespacial das metrópoles brasileiras; identifica mudanças significativas ocorridas nas últimas décadas, mas chama a atenção também para várias continuidades no que se refere às desigualdades socioespaciais.

Palavras-chave: Ordem espacial. Metrópoles. Desigualdades espaciais. Centros. Periferias.
\end{abstract}

Pesquisadores de vários países têm despendido esforços para a compreensão das mudanças ocorridas na ordem espacial das metrópoles nas últimas décadas do século passado, em consequência do processo de globalização e da nova ordem econômica mundial. A importância desses estudos deve-se ao fato de a organização espacial urbana não ser apenas um reflexo dessas forças, mas uma dimensão importante da ordem social, uma vez que implica oportunidades e riscos, define lugares sociais, aumenta ou diminui as chances das pessoas, seja por questões objetivas, como proximidade ou facilidade de acesso ao trabalho, seja por questões subjetivas, como as discriminações advindas das representações sobre os diferentes territórios das cidades. Esses esforços analíticos deram origem a distintas explicações, ora enfatizando mais os aspectos econômicos, ora os socioculturais. Cidade pósmoderna, fractal, dual, dividida, mundial e pós-metrópole são algumas das denominações

* Pontifícia Universidade Católica (PUC) Minas. Departamento de Ciências Sociais e do Programa de Pós-graduação em Ciências Sociais.

Avenida Itaú, 505. Dom Cabral. Cep: 30535012. Belo Horizonte - Minas Gerais - Brasil. lucianatandrade1@gmail.com criadas pelos estudiosos na tentativa de compreender e captar o que teria efetivamente mudado (Jamenson, 1996; Soja, 2000; Mollenkopf e Castells, 1991; Harvey, 1992; Sassen, 1998; Zukin, 1996; Marcuse e Van Kenpem, 2000). Outra vertente interpretativa ponderou que as transformações não seriam tão radicais a ponto de ensejar uma configuração totalmente nova, mostrando a permanência de formas de organização espacial anteriores e argumentando que o atual cenário seria uma combinação de mudanças com continuidades em função de uma relativa inércia das estruturas construídas, assim como das relações sociais (Beauregard e Haila, 2000 e Van Kempen, 2007). Como se vê, não há um consenso, principalmente porque, ainda que globais, as mudanças incidem em cidades com histórias e contextos distintos, o que contribui para que os seus efeitos não sejam homogêneos. ${ }^{1}$

${ }^{1}$ Ao questionar o papel homogeneizante da globalização
sobre a ordem espacial das cidades Van Kempen (2007)
enumera sete fatores que precisariam ser levados em conta
no estudo de cada cidade: ambiente físico, história, desen-
volvimento econômico, desigualdade, raça e racismo, po-
der político e governança. Já Banerjee-Guha (2010) chama
a atenção para a lógica hierárquica da globalização, que
tanto inclui quanto exclui países, cidades e áreas no inte-
rior das cidades. 
No Brasil, o chamado padrão de segregação centro-periferia marcou o debate sobre a ordem espacial por algumas décadas, ainda que frequentemente tenha sido objeto de críticas comuns a representações duais, em geral, simplificadoras. ${ }^{2}$ Originalmente, periferia e centro compunham os pares de um modelo analítico que teve início com a intensificação dos processos de urbanização e metropolização brasileiros a partir dos anos 1960 e que resultou em uma organização das metrópoles com áreas muito distintas em relação à renda de seus habitantes e à infraestrutura. As chamadas áreas centrais foram caracterizadas como aquelas que concentravam os grupos de alta e de média renda e que contavam com boa infraestrutura urbana, oferta de serviços e de empregos. Nesse sentido, tratava-se da área central e não apenas do centro histórico das cidades, esse mais próximo da categoria bairro. Já as periferias se constituíram em locais afastados dessas benfeitorias, mas, ao mesmo tempo, acessíveis economicamente como locais de moradia para as populações de baixa renda, na ausência de uma política habitacional pública. ${ }^{3}$

Atualmente, a crítica a esse modelo acentuou-se em função de várias mudanças que teriam ocorrido nas metrópoles brasileiras tornando-as mais complexas socioespacial๑ mente e também por influência do debate inస్ ternacional. Isso não significou o abandono das categorias centro e periferia, tratadas, agoสี่ $\mathrm{ra}$, não como pares exclusivos de uma ordem espacial, mas como territórios da metrópole.

$\stackrel{-}{ }{ }^{2}$ Outro tipo de crítica dirigida às representações duais, ¿. mas não só a elas, foca a questão hierárquica. No Brasil, há

$\overbrace{}^{\circ}$ uma discussão, mais forte no campo cultural, que questio-

$\curvearrowright$ na a suposta hierarquia do centro, argumentado sobre as

$\therefore$ potencialidades criativas da periferia (Cf. VIANNA, 2007).

के Outra crítica se dirige aos modelos que procuram hierar-

$\checkmark$ quizar as metrópoles, como os das cidades mundiais e glo-

$>$ bais. Uma das primeiras reflexões nessa direção pode ser

ธิ encontrada em King (1990) e uma revisão atual do debate em Robinson (2002).

que a periferia tenha sido preponderantemente - obra da iniciativa privada - loteadores privados - combi-

İ nada com a autoconstrução das moradias, a ação do Esta-

ઉ do não pode ser desconsiderada, seja pela falta de controle

sobre essa ocupação, seja abrindo os caminhos e levando,

mesmo que a posteriori, a infraestrutura. Há de se consi-

derar ainda a construção, pelo Estado, de conjuntos habi-

$\circlearrowleft$ tacionais em várias periferias metropolitanas.
Além disso, os seus sentidos passam atualmente por uma revisão.

Segundo os pesquisadores brasileiros, a ordem espacial metropolitana, a partir os anos 1990, teria se tornado mais heterogênea, com algumas regiões apresentando maior mistura social, contrariando, portando, a homogeneidade que caracterizaria tanto as áreas centrais quanto as periferias. Essa ordem espacial teria se tornado também mais fractal ou mais fragmentada com a proximidade, ainda que em forma de enclaves, de grupos de diferentes níveis socioeconômicos. As principais evidências empíricas desse debate podem ser sintetizadas em quatro. A primeira trata da presença dos condomínios fechados para população de média e de alta renda em algumas periferias das metrópoles, ou seja, um deslocamento de uma parte da população que vivia nas áreas centrais para as periferias metropolitanas, o que as teria transformado em espaços mais heterogêneos (Caldeira, 2000; Costa, 2006). A segunda chama a atenção para a existência de espaços pericentrais ocupados pelos grupos de média renda e localizados entre os espaços centrais e as periferias. Tal presença teria sido minimizada frente à força da representação dual (Ribeiro, 2002). A terceira trata de mudanças nas áreas centrais relacionadas à composição da sua população e às atividades econômicas. No primeiro caso, parte da área central, que teve sua qualidade de vida afetada por fatores como trânsito, barulho, poluição e violência, perdeu população de médio estrato e passou a atrair população de mais baixo status socioeconômico, seja como residente, ocupante de prédios abandonados, moradora de rua, além da manutenção ou intensificação das tradicionais áreas de prostituição e as novas de consumo de drogas como o crack. ${ }^{4}$ No segundo caso, ainda que seja um fato intimamente relacionado à perda da parcela de médio status,

${ }^{4}$ Esse tipo de uso do espaço, presente em algumas capitais brasileiras, mas não em todas, pode ser encontrado em partes muito específicas do centro histórico. Exemplos de distintas territorializações do crack já foram estudados por Frúgoli Jr. e Cavalcanti (2013) e Medeiros (2010) e da prostituição por Jayme, Chacham e Morais (2013). 
parte da área central, mais especificamente, o centro histórico das metrópoles, perde importância econômica com a transferência de seu comércio e serviços mais sofisticados para os shopping centers e outras áreas da cidade, o que dará início ao surgimento de novas centralidades em diferentes partes do território metropolitano. Outro fator que, apesar de não ser novo, evidencia a heterogeneidade do centro é a presença das favelas, o que passou a ser mais contemplado pela literatura à medida que se reforça o argumento da diferenciação das áreas centrais, subsumido pela representação dual, mas também em função da conquista do direito dos moradores das favelas de permanecerem onde estão em contraposição às políticas de remoção. Por fim, a quarta evidência trata da mudança na infraestrutura das periferias, o que altera um dos seus elementos originalmente definidores: a precariedade. Se, antes, as periferias foram caracterizadas como espaços de carência (Maricato, 1979), hoje, seus indicadores de infraestrutura urbana - água, luz, esgoto e demais serviços urbanos - não as diferenciam de forma significativa das áreas centrais (Torres; Marques, 2001). Com essas mudanças, as periferias passaram a atrair empreendedores imobiliários e os grupos médios, o que também contribuiu para a sua maior heterogeneidade (Caldeira, 2000; Ribeiro, 2002; Costa e Mendonça, 2011; Lago, 2011). Esse processo não ocorreu de forma homogênea em todo o território metropolitano, daí a pertinência, como se discutirá ao longo do texto, de se falar atualmente de periferias no plural, dada à sua maior diferenciação interna.

O reconhecimento das mudanças nas periferias não significou a substituição ou o abandono da categoria periferia, ${ }^{5}$ mas o acréscimo de algum adjetivo: novas periferias (Costa, 2006), hiperperiferias ${ }^{6}$ (Torres; Marques,

5 Uma prova são coletâneas como Sobre periferias: novos conflitos no Brasil contemporâneo (Vieira e Feltran, 2013) e outros livros e artigos que tratam de temas específicos tais como comunicação, arte, entre outros, além de blogs, teses e dissertações.

${ }^{6}$ Categoria utilizada para distinguir as novas periferias precárias (hiperperiferia) das mais antigas "[...] crescente-
2001) e periferias consolidadas (Saraiva, 2008) são alguns deles. Em relação ao centro, a literatura, ainda que mais restrita, trata das mudanças no centro histórico das cidades, mas também e, em menor número, da emergência de novas centralidades (Frúgoli Jr., 2000; Tonucci Filho, 2009; Soares e Schneider, 2012).

Duas hipóteses podem explicar, neste momento, a maior atenção da literatura para a discussão das mudanças nas periferias em detrimento das mudanças no centro. Primeiramente, devido ao maior interesse, nos anos 1970 e 1980, pelas investigações da vida nas periferias em função da novidade e dos desafios que colocavam para a urbanização, o que gerou um número muito maior de estudos sobre elas, comparativamente àqueles dedicados às áreas centrais, criando-se, portanto, uma tradição de estudos sobre as periferias. Em segundo lugar, porque as mudanças nas áreas centrais são mais incipientes. Diferentemente do que ocorreu em muitas capitais europeias e em algumas cidades norte-americanas, as áreas centrais das grandes cidades brasileiras não passaram por intensos processos de gentrification (Smith, 1996; Zukin, 1996) que pudessem estimular estudos sobre elas. A principal mudança em relação aos deslocamentos espaciais das classes média e alta se deu em direção aos condomínios fechados. E, ainda que bairros específicos das metrópoles tenham passado por processos de elitização, com elevação do padrão das moradias e dos moradores, eles são distintos daqueles que configuraram stricto sensu o fenômeno da gentrification. ${ }^{7}$

Sintetizando, essas mudanças teriam levado à constituição de espaços mais fragmentados, ou fractais, e mais heterogêneos socialmente integradas em termos urbanos." (Torres e Marques, 2001, p. 3).

${ }^{7}$ Há um conjunto de estudos que analisa a desconcentração, mas com foco prioritário nas atividades econômicas, e outro conjunto que foca processos específicos de mudancas nos centros históricos de algumas capitais, discutindo as questões relativas à renovação e (ou) gentrification desses espaços. Alguns exemplos desses estudos, pelo viés econômico: Diniz e Campolina (2007) e Simões e Amaral (2011) e de renovação urbana: Leite (2004), Rubino (2009) Frúgoli Jr. Sklair (2009). 
mente. Fala-se, portanto, de periferias no plural e de múltiplas centralidades, além de outros espaços mais heterogêneos que abrigariam preponderantemente os grupos médios. ${ }^{8}$ Em relação às novas centralidades, algumas ainda estariam por acontecer como resultado de recentes investimentos estatais e (ou) privados.

Se o modelo centro-periferia teve uma virtude, inclusive política, de chamar a atenção para as desigualdades sociais, a atual configuração mais heterogênea e mais fragmentada não deve levar a uma leitura de que a ordem espacial metropolitana tenha se tornado mais igualitária. Em muitos casos a proximidade de grupos diferentes tem levado a um aumento da tensão e a políticas segregadoras de fechamento de áreas públicas, como também de controle de certas práticas, como o comércio informal e a ocupação de espaços públicos por moradores de rua. O que se percebe são novas formas de organização das desigualdades, algumas delas levando, inclusive, à intensificação da segregação e do conflito pela complicada proximidade dos diferentes grupos sociais. Alguns autores têm utilizado a denominação cidades divididas como uma alternativa a cidade dual. Ainda que a divisão das cidades não seja um fato novo e que todas as cidades sejam, de alguma forma, divididas, ela chama a atenção para a ๑ separação e (ou) segregação que existem entre ণ os diferentes grupos sociais, mas, ao mesmo tempo, não as reduz a uma divisão dual. Van สี Kempen (2007, p. 15) assim define as cidades divididas: "Divided cities imply the existence of different areas within a city. These all have different characteristics; they may be pros$\Leftrightarrow$ perous or poor, deprived or privileged, old or a new, dominated by high rise apartment blocks, oे or by single family homes, or contrasted on $\therefore$ countless other factors."

Considerando as mudanças acima descritas, mas, ao mesmo tempo, a continuidade

${ }^{8}$ Os espaços metropolitanos brasileiros, com raras exceções, abrigam diferentes grupos sociais. O que permite nomear um espaço, tendo como referência um grupo social, é a predominância de um grupo em relação a outros, mas não sua exclusividade (Ribeiro, 2003). do emprego das categorias periferias e centro (ou área central), ainda que de forma distinta da sua gênese nos anos 1970, este artigo procurará compreender, prioritariamente por meio de estudos realizados com os dados do Censo de 2010, as mudanças nos espaços centrais e nos periféricos das metrópoles brasileiras. Maior ênfase será dada às periferias, uma vez que grande parte da literatura relaciona as atuais transformações na ordem espacial metropolitana às mudanças nas periferias, como foi mostrado anteriormente. De toda forma, a periferia não será analisada isoladamente, mas em relação a outros espaços metropolitanos. Como partes de uma ordem espacial, os espaços são relacionais, e as mudanças em um precisam ser vistas em relação a outros. Há de se ponderar, entretanto, que essas mudanças têm muitas dimensões e que os dados apresentados a seguir captam apenas uma parte, justamente aquela mais abrangente e possível de ser revelada pelos dados censitários. A dimensão da sociabilidade, por exemplo, não será aqui contemplada.

A partir dessas considerações analíticas, o texto desenvolve a hipótese de que a ordem espacial brasileira mudou, que o modelo centro-periferia é insuficiente para descrevê-la, mas, ao mesmo tempo, chama a atenção para algumas importantes continuidades.

O texto está estruturado do seguinte modo. Numa primeira parte, apresenta o atual cenário das regiões metropolitanas brasileiras à luz de dois recentes estudos, assim como as questões metodológicas envolvidas. Vai se valer, tanto nessa primeira parte como na seguinte, de estudos do Instituto Brasileiro de Geografia e Estatística (IBGE), do Observatório das Metrópoles e do Mapa da Violência, em função de suas abordagens nacional e metropolitana. Foram esses estudos que permitiram contemplar, no espaço deste artigo, vários indicadores relacionados aos diferentes aspectos da ordem espacial metropolitana. Na segunda parte, o texto se detém na compreensão das mudanças e das continuidades nos espaços metropolita- 
nos por meio de três tipos de indicadores: demográficos, de infraestrutura e de violência. Em todos os tópicos, a apresentação geral das tendências das regiões metropolitanas brasileiras será seguida de um foco sobre a região metropolitana de Belo Horizonte, em função de ser esse o local das minhas pesquisas e porque, ainda que o fato metropolitano esteja presente em todo o território nacional, há diferenças internas, históricas e contextuais, que tornam temerárias certas generalizações. No final, o texto retoma as questões analíticas sobre a ordem espacial apresentadas nesta introdução.

\section{AS REGIÕES METROPOLITANAS NO BRASIL: como apreendê-las?}

O Brasil tem hoje uma rede bastante complexa de regiões metropolitanas, com tamanhos e relevância econômica, social, política e cultural muito diferenciada. Em 2012, o País contava com um conjunto de 51 regiões metropolitanas institucionalizadas, três Regiões Integradas de Desenvolvimento (RIDE) e cinco Aglomerações Urbanas (AU), totalizando 59 espaços (Observatório das Metrópoles, 2012). Entre eles, há metrópoles nacionais, regionais e, até mesmo, locais.

A institucionalização das regiões metropolitanas no Brasil aconteceu na década de 1970 por meio de uma legislação federal que criou nove regiões metropolitanas. ${ }^{9} \mathrm{Com}$ a Constituição Federal de 1988, a competência para criar e realizar mudanças nas regióes metropolitanas passou a ser exercida pelos estados federados. O resultado foi uma proliferação de regiões metropolitanas, assim como o inchaço de muitas delas (Faria, 2012). Parte desse processo é resultado do crescimento urbano metropolitano, mas grande parte foi feita à sua revelia, ou seja, pautou-se, predominan-

${ }^{9}$ A Lei Complementar n. 14, de 8/06/1973, instituiu oito RMs: Belém, Belo Horizonte, Curitiba, Fortaleza, Porto Alegre, Recife, Salvador e São Paulo, e a Lei Complementar n. 20, de 1/07/1974 incorporou o Rio de Janeiro entre elas. temente, por critérios de natureza política. A questão que se coloca hoje para os investigadores é como separar o que é metropolitano do que não é. O Instituto Brasileiro de Geografia e Estatística (IBGE) e o Observatório das Metrópoles (OM) realizaram estudos que buscaram aferir a hierarquia dessas regiões, com o intuito de identificar o que pode ser considerado como metropolitano, na realidade urbana brasileira.

Esses estudos chegaram a um conjunto bem mais reduzido, em relação às RMs institucionalizadas. O Estudo de Influência das Cidades - REGIC (IBGE, 2008, p. 11) - considerou como metropolitanas 12 regiões ${ }^{10}$ caraterizadas "[...] por seu grande porte e por fortes relacionamentos entre si, além de, em geral, possuírem extensa área de influência direta." Em 2009, o Observatório das Metrópoles (OM), no estudo Níveis de integração dos municípios brasileiros em RMs, RIDEs e AUs à dinâmica da metropolização, obteve como resultado um conjunto de 15 espaços metropolitanos (Ribeiro, 2009). ${ }^{11}$ Em 2012, o OM refez o estudo de 2009 com os dados do Censo de 2010 e, no plano nacional, seguiu a hierarquização do REGIC com 12 espaços..$^{12}$ Como o REGIC, destacou o papel de centralidade na definição de metrópole "[...] a metrópole é considerada a partir de características desses aglomerados que lhes permitem constituírem-se como centros do poder econômico, social e político. Portanto, são unidades capazes de polarizar o território nas escalas nacional, regional e local" (Observatório das Metrópoles, 2012, p. 2). Ambos destacam o poder de polarização das metrópoles no território nacional e a intensidade de trocas que se efetivam interna e externamente. ${ }^{13}$

${ }^{10}$ Além das nove criadas na década de 1970, considerou também Brasília, Goiânia e Manaus.

${ }^{11}$ Além das 12 identificadas pelo REGIC, também incluiu Vitória, Campinas e Florianópolis.

${ }^{12}$ Apesar de o OM ter seguido a classificação do REGIC no estudo de 2012, com 12 RMs, ele retomará a antiga classificação do estudo de 2009, com 15 RMs, em outros estudos, como no IBEU, que será apresentado na parte sobre a infraestrutura.

${ }^{13}$ Esses estudos utilizaram vários indicadores (demográficos, econômicos e de interação entre os municípios) capazes de aferir a centralidade exercida pelas metrópoles e, 
Entretanto, as dificuldades para a compreensão da realidade metropolitana não se encerram na distinção acima apresentada. Outro desafio refere-se às distintas escalas dos dados disponíveis. Alguns têm como escala o município, não permitindo, portanto, a compreensão de uma realidade com muitas desigualdades espaciais. Nesse caso, tentar-se-á completar a análise com outros dados que se aproximam da escala dos bairros ou regióes dentro de um mesmo município. Para efeitos da análise que será aqui apresentada, no caso dos dados em escala municipal, o município-polo será tratado como um tipo de centralidade e, em relação aos outros municípios, serão utilizadas as agregações pelo grau de integração metropolitana, para não analisá-los como se fossem um todo homogêneo. ${ }^{14}$ No segundo caso, já será possível refinar a análise por meio da distinção entre diferentes tipos de espaços no interior do polo assim como nos municípios metropolitanos.

Essas duas questões dizem respeito a vários outros estudos, e não especificamente ao que está sendo aqui realizado. Uma última relaciona-se diretamente à tentativa de compreensão de espaços que, apesar de distintos, são interdependentes. A fragmentação em centros, periferias, favelas, subcentros, espaços ๑ pericentrais ou qualquer outra denominação సั. não os faz universos independentes, pois integram uma mesma ordem espacial com diferenฐี tes níveis de interações sociais. Até mesmo os condomínios fechados recebem diariamente

- no caso do estudo do OM, aferiu-se também a hierarquia ¿ e o grau de integração dos municípios no interior de cada

के metrópole. A metodologia de cada um está disponível para

․ consulta na internet, conforme as referências bibliográfi-

$\stackrel{\circ}{ }$ cas.

14 Tendo como hipótese que as atuais regiões metropolitanas institucionalizadas não são a expressão do efetivo స్ fenômeno urbano-metropolitano, o Observatório das $\mathrm{Me}$ trópoles construiu o indicador grau de integração à dinâIJ mica da metropolização, com o objetivo de distinguir os 先 municípios efetivamente metropolitanos dos não metropolitanos. Os diferentes graus de integração que vão do polo, passando por municípios com alta, média e baixa integração, aferiram a inserção de cada município das unidades institucionalizadas à dinâmica metropolitana. há, em todos os espaços (em uns mais do que em outros), interações e trocas entre os diferentes habitantes da metrópole.

Para a discussão da atual configuração espacial das metrópoles, elegeram-se três tipos de indicadores. O primeiro grupo reúne indicadores econômicos e demográficos e tem como objetivo conferir e comparar as taxas de crescimento demográfico, a capacidade de atração ou de dependência dos municípios e o seu o poder econômico. O segundo avalia a atual situação da infraestrutura urbana e o terceiro, a violência. Esse último indicador tem, como um de seus efeitos, a estigmatização de territórios e de pessoas.

\section{DINÂMICAS METROPOLITANAS: mudanças e continuidades}

Para a caracterização econômica, demográfica e de integração, a fonte dos dados é o estudo Níveis de integração dos municípios brasileiros em RMs, RIDES e AUS à dinâmica da metropolização (Observatório das Metrópoles, 2012), que teve como universo as 59 regiões metropolitanas, Rides e Aglomerações Urbanas. ${ }^{15}$ Tais indicadores têm como referência espacial os municípios. Por isso mesmo, será tratado aqui como centro o município-polo e, em função da heterogeneidade dos outros municípios metropolitanos, serão utilizados como critério de agregação e diferenciação os seus graus de integração à dinâmica metropolitana. No estudo do OM, os 945 municípios estudados foram classificados em sete níveis hierárquicos de integração: Polo, Extensão do

${ }^{15}$ Os indicadores utilizados para aferir o grau de integração foram: grau de concentração e distribuição de população, produto, rendimentos e fluxos de população em movimentos pendulares para trabalho e (ou) estudo entre municípios das aglomerações, assim como realização de funções específicas e fundamentais para a realização das atividades econômicas e suporte aos fluxos interaglomeracões, como a presença de portos e aeroportos. Em relação à análise estatística, os procedimentos utilizados foram: Análise por Componentes Principais (ACP) e Análise de Cluster por Classificação Hierárquica Ascendente. Para mais detalhes a respeito da metodologia, ver o estudo, assim como á descrição dos testes realizados no Anexo I (OBSERVATÓRIO DAS METRÓPOLES, 2012). 
polo, Muita alta, Alta, Média, Baixa e Muito baixa. Até a integração Média, eles foram considerados como efetivamente metropolitanos (437 municípios); já os níveis de integração Baixo e Muito baixo como não metropolitanos (508 municípios). (Observatório das Metrópoles, 2012).

\section{INDICADORES DEMOGRÁFICOS}

Comparando-se os municípios-polo com os outros segundo o grau de integração, chama a atenção a centralidade que os polos continuam a exercer em termos de geração e concentração de renda, e também pela presença de portos e aeroportos, importantes no suporte aos fluxos econômicos e de pessoas. Os polos concentram 60,7\% do PIB e 66,5\% da renda. Dos 39 aeroportos e dos 30 portos presentes em todos os municípios das aglomerações pesquisadas, os polos concentram 33 a década de 1980. Esse cenário contrasta com as décadas de 1950, 1960 e 1970 com altas taxas de crescimento devido, principalmente, a uma forte corrente migratória, primeiro para as periferias do município-polo e depois para os municípios vizinhos. A Tabela 1 mostra as taxas de crescimento dos polos de 15 metrópoles entre 1950 e $2010 .{ }^{16}$

Se os polos não são hoje mais atrativos do ponto de vista da moradia, seja pela alta concentração habitacional, seja pelo alto custo monetário da moradia e da terra, as chamadas deseconomias da aglomeração, há um grupo de municípios, classificados como de Alta integração ao polo (102 do universo de $945 \mathrm{mu}$ nicípios), que apresentou, em 2010, taxas relativamente altas de crescimento, 3,36. Um fator que justifica a atratividade desses municípios é sua densidade demográfica baixa (786,8 habitantes por $\mathrm{km}^{2}$ ), quando comparados aos municípios hierarquicamente superiores do ponto de vista da integração metropolitana, os

Tabela 1 - Taxa de crescimento populacional entre 1950 e 2010

\begin{tabular}{|c|c|c|c|c|c|c|}
\hline RMs & $1950-1960$ & $1960-1970$ & 1970-1980 & 1980-1991 & $1991-2000$ & 2000-2010 \\
\hline Belém & 4,42 & 4,71 & 4,31 & 3,21 & 2,51 & 1,29 \\
\hline B. Horizonte & 5,18 & 6,41 & 4,51 & 2,77 & 2,15 & 1,14 \\
\hline Campinas & 4,95 & 5,10 & 6,49 & 3,87 & 2,28 & 1,81 \\
\hline Curitiba & 5,25 & 4,71 & 5,38 & 3,21 & 2,79 & 1,36 \\
\hline Florianópolis & 2,47 & 2,41 & 3,78 & 3,72 & 2,88 & 2,17 \\
\hline Fortaleza & 5,12 & 4,55 & 4,23 & 3,81 & 2,20 & 1,68 \\
\hline Goiânia & 8,62 & 8,38 & 6,26 & 3,95 & 2,88 & 2,26 \\
\hline Vitória & 5,34 & 6,86 & 6,07 & 4,19 & 2,38 & 1,60 \\
\hline P. Alegre & 3,61 & 3,90 & 3,49 & 2,73 & 1,42 & 0,63 \\
\hline Recife & 4,24 & 4,09 & 2,71 & 2,04 & 1,35 & 1,00 \\
\hline Ride DF & & & 7,15 & 3,58 & 3,19 & 2,31 \\
\hline Rio de Janeiro & 4,21 & 3,53 & 2,44 & 1,13 & 1,05 & 0,87 \\
\hline Salvador & 4,36 & 4,73 & 4,30 & 3,39 & 1,90 & 1,32 \\
\hline São Paulo & 5,94 & 5,51 & 4,46 & 2,07 & 1,47 & 0,96 \\
\hline 15 RMs & 4,83 & 4,99 & 4,01 & 2,40 & 1,76 & 1,20 \\
\hline Brasil & 3,06 & 2,87 & 2,38 & 2,11 & 1,45 & 1,16 \\
\hline \multicolumn{7}{|c|}{ Fonte: IBGE. Dados trabalhados pelo Observatório das Metrópoles. } \\
\hline \multicolumn{7}{|c|}{$\begin{array}{l}\text { aeroportos e } 15 \text { portos. Paralelamente, verifi- } \quad \begin{array}{l}{ }^{16} \text { Sobre a tese que o centro de São Paulo teria voltado a } \\
\text { crescer nos anos 2000, ver Marques (2013), que mostra a } \\
\text { ca-se um crescimento populacional baixo dos }\end{array} \\
\text { polos }(1,15) \text { em relação aos outros municípios } \begin{array}{l}\text { sentando crescimento moderado, outras intenso e outras } \\
\text { esvaziamento continuado: "contrariando a ideia de que ge- } \\
\text { nericamente o centro teria voltado a crescer" (2013, p. 36). }\end{array}\end{array}$} \\
\hline
\end{tabular}


com Muito alta integração $\left(2.065,2 \mathrm{hab} / \mathrm{km}^{2}\right)$, extensão dos polos $(5.164,1)$ e polos $(3.676,7)$.

Hierarquicamente, na frente dos municípios com Alta Interação, estão os municípios classificados como extensão dos polos e com Muito Alta integração, cuja dinâmica populacional se aproxima do polo. São municípios que cresceram muito nas décadas passadas e agora apresentam taxas de crescimento inferiores às do grupo dos municípios com Alta integração, justamente por já estarem bastante adensados.

Os dados sobre o movimento pendular - pessoas que se deslocam cotidianamente do seu município de residência para outro município para trabalho ou estudo - completam os dados do crescimento populacional na caracterização da dinâmica metropolitana. Os municípios-polo concentram 40\% dos fluxos, mas com prioridade absoluta para os de entrada $(74,6 \%)$, o que confirma sua centralidade na

oferta de empregos e de serviços educacionais. Os municípios classificados como Extensão dos polos têm uma atratividade ligeiramente superior à dos municípios com Muito alta e Alta integração, confirmando sua capacidade maior de atração. Já os de Muito alta integração destacam-se pelos altos fluxos de saída $(71,1)$. São municípios cuja função primeira, no contexto metropolitano, é a da moradia, uma vez que dependem de outros municípios, em geral, dos polos, para trabalho e estudo. Os de Média e Baixa integração apresentam perfil muito semelhante com fluxos de entrada próximos de $30 \%$ e de saída em torno de $70 \%$. Os de Muito Baixa integração dependem menos, comparativamente dos outros, mas, de toda forma, é alto o volume de saída, $65,6 \%$.

Os 20 municípios classificados como Extensão dos polos se caracterizam por um

[...] avançado processo de metropolização, com uma dinâmica de integração altíssima, tanto na escala regional quanto na nacional. Esses municípios, jun-

Tabela 2 - Grupos de municípios por níveis de integração segundo dimensões urbanas e de crescimento populacional

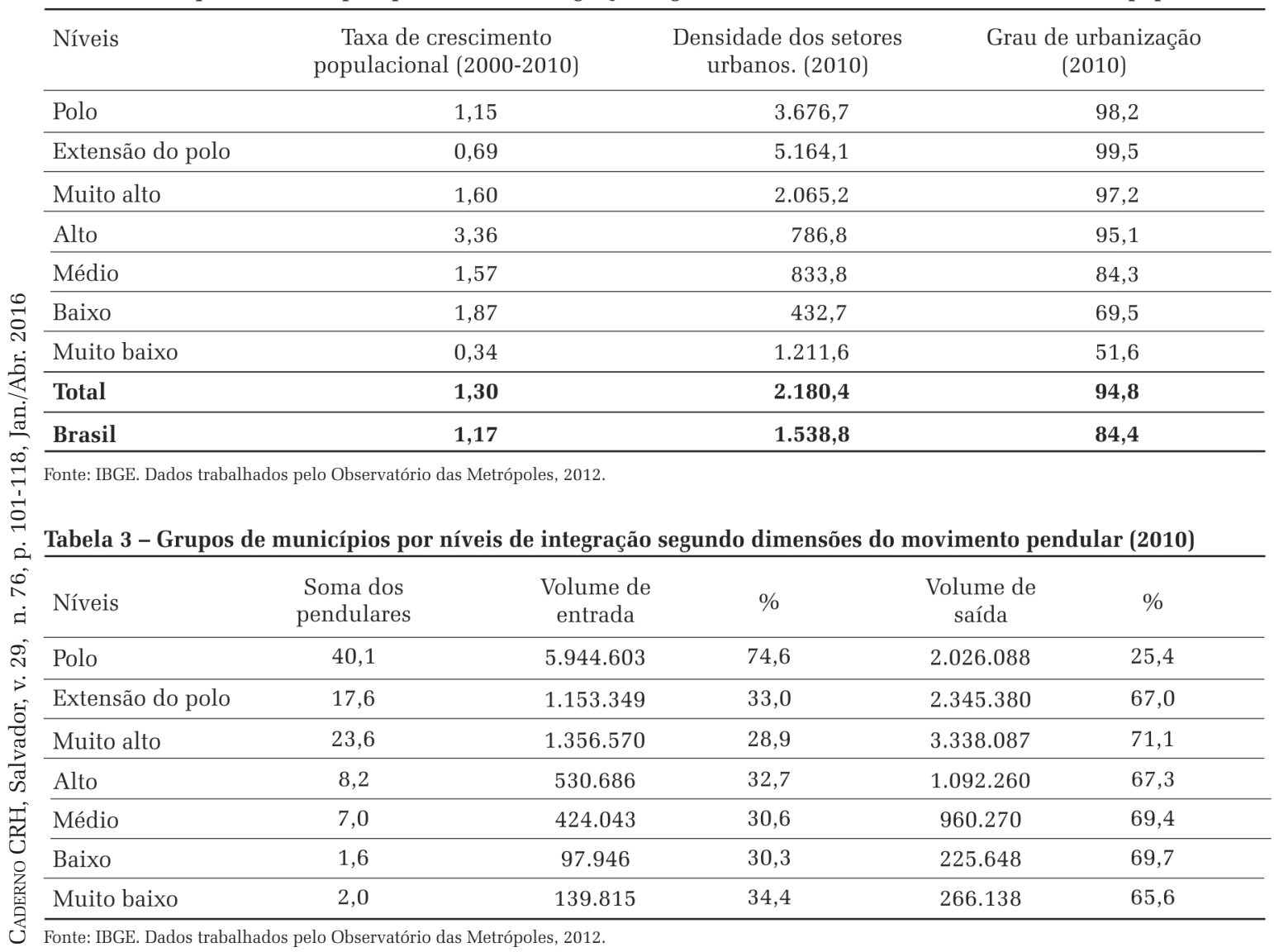


tos, reúnem expressiva parcela da população, produção de riqueza e apropriação de renda no País" (Observatório das Metrópoles, 2012, p. 3).

Por essas razões, eles podem ser percebidos como a expressão de um processo de desconcentração dos polos, uma vez que também exercem funções de centralidade. Por outro lado, o crescimento dos municípios com Alta integração é um indicador de processos de extensão das periferias metropolitanas. ${ }^{17} \mathrm{De}$ onde se conclui que há movimentos levando à emergência de novas centralidades, como outros movimentos em direção à expansão das periferias, de espraiamento e de continuidade da periferização da população sem acesso às áreas centrais das regiões metropolitanas.

Focando agora a Região Metropolitana de Belo Horizonte (RMBH) ${ }^{18}$, o município-polo, Belo Horizonte, cresceu 0,59 na década. Os municípios com Muito alta integração, 2,1 e os de Alta integração, 2,5. Diferentemente dos resultados nacionais, para a $\mathrm{RMBH}$, verifica-se um crescimento apenas ligeiramente superior ao dos municípios com Alta integração em relação aos de Muito alta, mas ambos superiores ao crescimento total da RMBH $(1,14)$. Em
Belo Horizonte concentra os fluxos de entrada, e os municípios com Alta integração caracterizam-se pelos altos fluxos de saída somados à baixa atratividade (fluxo de entrada). ${ }^{19}$

Os dados de Belo Horizonte mostram, como os nacionais, que o polo Belo Horizonte continua a exercer sua função de polarização do movimento pendular, ou seja, concentra postos de trabalho e de instituições de ensino. Os municípios com Muito alta integração são, depois do polo, os que apresentam maior fluxo de pessoas, mas com predomínio dos fluxos de saída $(68,7 \%)$. Com valores absolutos menores, mas com taxa ainda maior de saída (83,7\%), estão os municípios com Alta integração. Ambos concentram 52,6\% dos fluxos da RMBH, ou seja, um alto número de pessoas que experimenta a desconexão entre lugar de moradia e local de trabalho. Essa é uma característica das periferias metropolitanas. Nesse conjunto, estão representadas periferias mais antigas e novas, mas o que se nota é a manutenção de dependência em relação ao trabalho em outro município. Nesse aspecto e analisados relacionalmente, esses municípios permanecem como cidades-dormitório da $\mathrm{RMBH} .{ }^{20}$

Tabela 4 - Grupos de municípios da RMBH por níveis de integração segundo dimensões do movimento pendular (2010)

\begin{tabular}{lccccc} 
Níveis & $\begin{array}{c}\text { Soma dos } \\
\text { pendulares }\end{array}$ & $\begin{array}{c}\text { \% Soma dos } \\
\text { pendulares }\end{array}$ & Entrada (\%) & Saída \% & $\%$ \\
\hline Polo & 553.227 & 42,1 & $449.449(81,2)$ & $103.778(18,8)$ & 100 \\
\hline Muito alto & 537.972 & 40,9 & $168.309(31,3)$ & $369.663(68,7)$ & 100 \\
\hline Alto & 153.069 & 11,7 & $24.915(16,3)$ & $128.154(83,7)$ & 100 \\
\hline Médio & 60471 & 4,6 & $17.690(29,3)$ & $42.781(70,7)$ & 100 \\
\hline Baixo & 6647 & 0,5 & $3.022(45,5)$ & $3.625(54,5)$ & 100 \\
\hline Muito baixo & 2334 & 0,2 & $790(33,8)$ & $1.544(66,2)$ & 100 \\
\hline Total & 1.313 .720 & 100,0 & & & \\
\hline
\end{tabular}

Fonte: IBGE. Dados trabalhados pelo Observatório das Metrópoles, 2012.

relação ao movimento pendular, já se verifica situação semelhante à do contexto nacional.

${ }^{17}$ Os dados de infraestrutura que serão apresentados a seguir caracterizarão melhor essas áreas de expansão na RMBH.

${ }^{18} \mathrm{O}$ núcleo de pesquisadores do $\mathrm{OM}$ da $\mathrm{RMBH}$ refez o estudo nacional do OM para a RMBH utilizando a mesma metodologia do estudo de 2009, que, no estudo de 2012, sofreu algumas alterações. O principal objetivo foi torná-los comparáveis no tempo. Mais detalhes do estudo podem ser encontrados em Diniz e Andrade (2015).
${ }^{19}$ Sobre o grau de integração dos municípios da RMBH, ver o capítulo escrito por Âlexandre Diniz e Luciana Andrade: Metropolização e hierarquização das relações entre os municípios da RMBH no livro Belo Horizonte: Transformações na ordem urbana (2015).

${ }^{20}$ Cidade-dormitório é outra denominação para periferias que enfatiza a sua dependência em relação a outros espaços da metrópole para trabalho e estudo. Como periferia é empregada para se referir aos territórios da pobreza, uma vez que não é usada, por exemplo, para se referir às cidades com alta presença de condomínios fechados e também com alta dependência de outros espaços metropolitanos. Sobre suas origens e usos ver Ojima et alii (2010). 
Ao analisar separadamente os movimentos pendulares dos municípios com Muito alta integração, notam-se processos distintos. Betim, cidade industrial como Contagem, tem um poder de atração de pessoas para trabalho e estudo proporcionalmente superior ao de Contagem, e ambos são altos em relação a esse grupo de municípios, respectivamente, 45,5 e 41,5, em 2010. Contudo, em ambos como em todos os outros municípios da RMBH, com exceção do polo, os fluxos de saída são maiores do que os de entrada. Nova Lima, cidade que abriga muitos condomínios fechados para grupos de média e alta renda, também tem um fluxo relativamente alto de entrada, 49,1, em 2010. Torna-se interessante atentar para a constituição aqui de um novo tipo de centralidade, distinta daquela presente nos municípios industriais como Betim e Contagem. Nova Lima reúne instituições de ensino superior, serviços e comércio sofisticado, instituições hospitalares e muitos empregos domésticos gerados pelas moradias em condomínios fechados (Andrade e Mendonça, 2010). Entre todos os municípios da RMBH, é o que apresentou maior crescimento dos fluxos de entrada na última década, passando de 35,9, em 2000, para 49,1, em 2010. Sendo um município com 81.162 habitantes, em números absolutos, esses fluxos são bem menores quando comparados aos సं de municípios com maiores como Contagem (603.442 hab.) e Betim (378.089 hab.), mas é สี significativo na medida em que aponta para o novas dinâmicas de atração de pessoas, não mais os empregos industriais, mas a prestação de serviços e os empregos domésticos. Vespasiano é um município que abriga uma grande periferia na sua fronteira com Belo Horizonte e cujo crescimento foi impulsionado pela construção de conjuntos habitacionais na década de 1980 (Nazario e Andrade, 2010), mas, diferentemente de Ribeirão das Neves e Ibirité, conta com atividades industriais, principalmente da indústria cimenteira. Dai a atração um pouco superior à desses dois municípios. Ribeirão das Neves é o típico município periférico da RMBH e cuja característica de cidadedormitório se mantém desde a década de 1960.

Observam-se, portanto, na RMBH, como no conjunto das RMs brasileiras, movimentos de desconcentração do polo e de extensão da periferia. Esse último é identificado aqui, principalmente, nos municípios com Alta integração, cujas densidades populacionais ainda são relativamente baixas. Notam-se, ainda, dinâmicas diferenciadas entre um grupo de municípios com crescimento intenso nas décadas de 1960 e 1970 devido à imigração, mas também expansões novas, como no caso de Nova Lima, que, por diversas razões, ambientais entre as principais (Andrade, 2003), teve sua ocupação controlada nas décadas de 1960 e 1970, fator que contribuiu, a partir dos anos 1980, para o crescimento dos condomínios fechados e para uma nova centralidade baseada nos serviços.

O estudo de Mendonça e Marinho (2015) sobre a estrutura socioespacial da RMBH na década de 2010 corrobora o que até aqui foi apresentado. Eles mostram uma continuidade da concentração espacial dos grupos supe-

¿. Tabela 5 - Movimento pendular nos municípios com muito alta integração da RMBH - 2000 e 2010

\begin{tabular}{|c|c|c|c|c|c|c|c|c|c|c|}
\hline \multirow{2}{*}{$\begin{array}{l}\text { Municípios } \\
\text { com muito alta } \\
\text { integração }\end{array}$} & \multirow{2}{*}{$\begin{array}{c}\text { Total de } \\
\text { fluxos }\end{array}$} & \multicolumn{4}{|c|}{2000} & \multicolumn{5}{|c|}{2010} \\
\hline & & $\begin{array}{c}\text { N. } \\
\text { entradas }\end{array}$ & $\begin{array}{c}\% \\
\text { entradas }\end{array}$ & $\begin{array}{c}\mathrm{N} \\
\text { saídas }\end{array}$ & $\begin{array}{c}\% \\
\text { saídas } \\
\end{array}$ & $\begin{array}{c}\text { Total de } \\
\text { fluxos }\end{array}$ & $\begin{array}{c}\mathrm{N} \\
\text { entradas }\end{array}$ & $\begin{array}{c}\% \\
\text { entradas }\end{array}$ & $\begin{array}{c}\mathrm{N} \\
\text { saídas }\end{array}$ & $\begin{array}{c}\% \\
\text { saídas } \\
\end{array}$ \\
\hline Betim & 58.129 & 24.957 & 42,9 & 33.172 & 57,1 & 98.858 & 44.946 & 45,5 & 53.912 & 54,5 \\
\hline Contagem & 132.137 & 49.383 & 37,4 & 82.754 & 62,6 & 195.159 & 80.973 & 41,5 & 114.186 & 58,5 \\
\hline Nova Lima & 12.995 & 4.666 & 35,9 & 8.329 & 64,1 & 30.370 & 14.904 & 49,1 & 15.470 & 50,1 \\
\hline Vespasiano & 18.825 & 4.151 & 22,1 & 14.674 & 77,9 & 34.762 & 7.572 & 21,8 & 27.190 & 78,2 \\
\hline Ibirité & 34.515 & 2.720 & 7,9 & 31.795 & 92,1 & 57.015 & 5.508 & 9,7 & 51.507 & 90,3 \\
\hline R. Neves & 63.049 & 3.989 & 6,3 & 59.060 & 93,7 & 97.427 & 7.848 & 8,0 & 89.579 & 92,0 \\
\hline
\end{tabular}


riores $^{21}$ no município de Belo Horizonte, mas também a sua expansão sobre o município de Nova Lima. Observa-se também a presença de grupos médios e médio superiores em algumas sedes municipais como as de Contagem, Betim e Nova Lima. Com esses dados, os autores qualificam essa desconcentração pela presença de grupos de alta e média renda em outros espaços que não apenas no polo. Já os grupos populares $^{22}$ continuam concentrados nas periferias da RMBH em um processo de “... permanente urbanização dos espaços periféricos.” (Mendonça e Marinho, 2015, p. 172).

\section{INFRAESTRUTURA URBANA}

Para a análise da infraestrutura urbana será usado o Índice de Bem-Estar Urbano (IBEU) calculado para 15 regiões metropolitanas do Brasil. ${ }^{23}$ Esse índice tem duas escalas. Na primeira, será possível comparar o bem-estar entre 15 RMs (IBEU Geral), mas o mais importante, para completar a análise mais geral anteriormente apresentada, é o fato de o IBEU contemplar as condições intraurbanas, desde que se concentre em uma região em particular; no caso deste artigo, e pelas razões já expostas, será a RMBH (IBEU Local). Na análise intraurbana da RMBH, será possível perceber as periferias presentes no interior da cidade-polo: Belo Horizonte, assim como as áreas centrais de alguns municípios que, por questões econômicas ou por maior diferenciação interna da sua população, têm algum poder de atração, ainda que em escala bem diferenciada daquela do polo. Será possível também comparar as

${ }^{21}$ Constituídos pelas categorias sócio-ocupacionais dos dirigentes dos setores público e privado e de profissionais de nível superior (Cf. MENDONÇA e MARINHO, 2015).

${ }^{22}$ Constituidos pelos operários da construção civil, trabalhadores de serviço não-especializado, domésticos, ambulantes e biscateiros.

${ }^{23}$ Belém, Belo Horizonte, Campinas, Curitiba, Florianópolis, Fortaleza, Goiânia, Grande Vitória, Manaus, Porto Alegre, Recife, Rio de Janeiro, Salvador, São Paulo e RIDE-DF. A fonte dessa seleção foi o primeiro estudo realizado pelo Observatório das Metrópoles sobre a integração metropolitana em 2009. condições de vida entre diferentes periferias da RMBH. ${ }^{24}$

Esse índice contemplou cinco dimensões da vida urbana: mobilidade, condições ambientais, condições habitacionais, atendimento de serviços coletivos urbanos e infraestrutura urbana. Cada uma dessas dimensões foi constituída por um conjunto de indicadores, tendo como fonte o Censo Demográfico de 2010. Os autores do estudo destacam, como uma de suas qualidades, a concepção do bem-estar urbano como um bem coletivo que deve ser usufruído e compartilhado por todos. "A concepção de bem-estar urbano presente neste trabalho que estamos propondo decorre da compreensão daquilo que a cidade deve propiciar às pessoas em termos de condições materiais de vida, a serem providas e utilizadas de forma coletiva." (Ribeiro e Ribeiro, 2013, p. 9). E, mesmo que sejam experimentadas individualmente e a partir de diferentes alternativas, como no caso da mobilidade, por exemplo, o impacto se faz sobre a vida coletiva. ${ }^{25}$

O IBEU varia entre zero e um: quanto mais próximo de um, melhor; quanto mais próximo de zero, pior. Trata-se de um índice comparativo entre as regiões metropolitanas (IBEU Geral) e entre os municípios e as áreas de ponderação de cada região metropolitana (IBEU Local). Ele mede, portanto, as distâncias entre essas diferentes unidades. Na análise comparativa das $15 \mathrm{RMs}$, o valor médio encontrado foi de 0,605. Campinas foi a única RM que apresentou índice superior a 0,8. Além de Campinas, outras oito RMs apresentaram valores acima da média: Florianópolis $(0,754)$, Curitiba $(0,721)$, Goiânia $(0,720)$, Porto Alegre $(0,719)$, Grande Vitória (0,699), Belo Horizonte $(0,658)$, São Paulo $(0,615)$ e RIDE-DF $(0,610)$, enquanto outras seis apresentaram índices abaixo da média. Entretanto, nesse grupo, é possível dis${ }^{24}$ Como se trata de uma medida em um momento específico no tempo, não será possível identificar com o IBEU as melhorias nas periferias. Em relação a essa mudança, o artigo contemplou outros estudos já realizados.

${ }^{25}$ Sobre a metodologia e o peso dos indicadores, ver capítulo 1 do estudo IBEU - Índice de bem-estar urbano (Ribeiro e Ribeiro, 2013). 
tinguir dois subgrupos: um com três RMs com índices próximos da média: Salvador $(0,573)$, Fortaleza $(0,564)$ e Rio de Janeiro $(0,507)$; e outro com três RMs com índices bem inferiores e que podem ser considerados ruins ou péssimos: Recife $(0,443)$, Manaus $(0,395)$ e Belém $(0,251)$.

Para a análise interna da $\mathrm{RMBH}$, que conta com 34 municípios, serão considerados apenas os municípios mais integrados à dinâmica metropolitana, ou seja, aqueles que foram considerados como metropolitanos. O que se pode perceber, por este estudo, é que as melhores condições estão fortemente concentradas em Belo Horizonte, em uma parte do município de Nova Lima, que concentra os condomínios, e nas áreas centrais de Betim e Contagem, os municípios industriais mais antigos da RMBH. Já as piores áreas estão em Ribeirão das Neves que, como foi mostrado anteriormente, permanece como município-dormitório, e em áreas relativamente próximas de Ribeirão das Neves, num processo que se pode chamar de expansão da periferia sobre uma parte do município de Esmeraldas. Esmeraldas está entre o grupo de municípios de Alta integração e com baixa densidade populacional, 380 hab. $/ \mathrm{km}^{2}$, ou seja, um município com capacidade de atração de novos moradores. Tal processo vem sendo verificado desde a década passada. Segundo os resultados ๑ aferidos pelo IBEU, $53,1 \%$ da população desసं sa expansão concentram as piores condições de bem-estar urbano (0,500 e 0,001). Passando (ี para o nível imediatamente a seguir $(0,700 \mathrm{a}$ 0,501), observa-se uma baixa qualidade de vida nas áreas periféricas de Belo Horizonte, o que evidencia a desigualdade interna ao polo, e em o várias porções do território metropolitano, com \& maior concentração no entorno da metrópole, oิ como em Ribeirão das Neves, Vespasiano, Santa

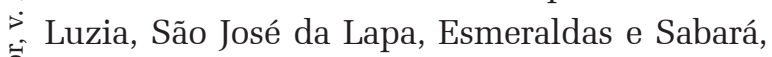
os primeiros no eixo Norte e o último no eixo Leste, mais Ibirité, Betim e Contagem no eixo İ Oeste. O que se conclui é que persiste a manutenção de uma baixa qualidade de vida tanto em algumas periferias tradicionais, como aquelas que se formaram na década de 1970, quanto em algumas novas periferias, como foi demonstrado por Esmeraldas.

O que se pode perceber, por esse índice comparativo, é que, apesar de a ordem socioespacial se apresentar de forma mais fragmentada espacialmente, as desigualdades permanecem. E, apesar da melhoria dos indicadores de infraestrutura urbana nas periferias, as distâncias em relação às áreas centrais continuam. Somase a isso o fato de que a periferia traz a marca da falta de planejamento, da falta de espaços públicos de qualidade e de controle na sua ocupação, uma realidade que se inscreve nas estruturas construídas. Se a autoconstrução foi o que viabilizou a casa própria para os imigrantes que chegavam às regiões metropolitanas, ela foi executada sob condições muito precárias e por uma população com poucos recursos econômicos. Há de se considerar também que a maior oferta de serviços públicos urbanos nas periferias, um indicador que as aproxima das áreas centrais e pericentrais, pouco diz sobre a sua qualidade (Torres e Marques, 2001). Para ficar com apenas um dos indicadores, mas dos mais importantes do ponto de vista da mobilidade social, a qualidade das escolas nas periferias é muito inferior à das outras áreas. Segundo o estudo Análise espacial dos indicadores educacionais de Belo Horizonte e região metropolitana, a região centro-sul de Belo Horizonte, a que reúne os grupos de mais alta renda, apresenta os melhores indicadores educacionais, com exceção das favelas. À medida que se afasta de Belo Horizonte, os indicadores pioram.

Esse processo espacial parece ser contínuo e ultrapassa os limites de Belo Horizonte de forma que os municípios próximos possuem taxas semelhantes às áreas periféricas de Belo Horizonte e os municípios mais distantes possuem indicadores piores ainda.” (Riane e Rios-Neto, 2007, p. 2).

\section{VIOLÊNCIA}

A violência nas metrópoles tem sido estudada com maior frequência por meio das 
taxas de homicídios, um crime de alta gravidade, mas que representa apenas uma dimensão da criminalidade urbana. Isso se deve, principalmente, ao acesso a esse dado de uma mesma fonte, o Sistema de Informações sobre Mortalidade (SIM), com cobertura nacional. Um limite desse dado é a sua escala municipal, da qual escapa a distribuição territorial de um fenômeno que é muito concentrado espacialmente (Andrade e Diniz, 2013 e Andrade, Souza e Freire, 2013). ${ }^{26}$

Depois do acelerado crescimento dos homicídios no País - iniciado na década de 1980 e que se manteve até o início dos anos 2000, mais precisamente até 2003 -, observase uma estabilização, mas com taxas em patamares ainda muito altos. Em 1980, a taxa de homicídios para 100 mil pessoas no País era de 11,7. Em 1990, passa para 22,2. 2003 é o ano de pico, com taxa de 28,9. Nos anos seguintes, as taxas oscilaram entre 25 e 27 homicídios por 100 mil habitantes. 2011 acusa uma taxa de 27,1 (Waiselfisz, 2013).

Essa estabilidade nacional dos últimos anos, aferida pelos dados nacionais, esconde mudanças significativas entre as regiões metropolitanas (Andrade, Souza e Freire, 2013). Como exemplo, as RMs do sudeste, que durante a década de 1980 apresentaram as mais altas taxas de homicídios, sofreram uma redução muito forte. Já as regiões metropolitanas do Norte e Nordeste mostraram as mais altas taxas de crescimento. Em ambos os casos, há diferenças internas às regiões. A queda no sudeste é muito expressiva na RMSP, até porque ela se fez sentir de forma mais homogênea, e não apenas na capital, como é o caso da RMRJ, que ainda mantém taxas altas nos municípios periféricos. Vitória e a RMV apresentam queda, mas as taxas ainda estão em patamares muito altos. O caso de Belo Horizonte destoa, uma vez que evidencia crescimento na capital, tendência oposta à das outras capitais do sudeste. Entre 2001 e 2011, os homicídios na cidade de São Paulo caíram quase 80\%. No Rio de

Tabela 6 - Taxa de homicídios por 100 mil habitantes nos municípios da RMBH com mais de 20 mil habitantes, por grau de integração

\begin{tabular}{l|c|c|c|c|c|c}
\hline Município & $\begin{array}{c}\text { População } \\
\text { em 2011 }\end{array}$ & $\begin{array}{c}\text { Taxa de } \\
\text { cresc. } \\
2000-2010\end{array}$ & $\begin{array}{c}\text { Posição na } \\
\text { hierarquia }\end{array}$ & $\begin{array}{c}\text { Número de } \\
\text { homicídios } \\
\text { em 2011 }\end{array}$ & $\begin{array}{c}\text { Taxa por } \\
100 \text { mil } \\
\text { em 2011 }\end{array}$ & Posição \\
\hline Belo Horizonte & 2.385 .640 & 0,59 & Polo & 961 & 40,3 & 7 \\
\hline Contagem & 608.715 & 1,15 & Muito alta & 239 & 39,3 & 9 \\
\hline Betim & 383.571 & 2,12 & Muito alta & 256 & 66,7 & 2 \\
\hline R. das Neves & 299.729 & 1,84 & Muito alta & 156 & 52,0 & 5 \\
\hline Ibirité & 160.943 & 1,80 & Muito alta & 64 & 39,8 & 8 \\
\hline Vespasiano & 106.685 & 3,18 & Muito alta & 57 & 53,4 & 3 \\
\hline Nova Lima & 82.273 & 2,32 & Muito alta & 18 & 21,9 & 12 \\
\hline Lagoa Santa & 53.645 & 3,33 & Alta & 3 & 5,6 & 15 \\
\hline Santa Luzia & 204.327 & 0,94 & Alta & 78 & 38,2 & 10 \\
\hline Sabará & 127.097 & 0,91 & Alta & 9 & 7,1 & 14 \\
\hline Esmeraldas & 61.283 & 2,50 & Alta & 43 & 70,2 & 1 \\
\hline Juatuba & 22.649 & 3,08 & Alta & 12 & 53,0 & 4 \\
\hline Sarzedo & 26.470 & 4,10 & Alta & 11 & 41,6 & 6 \\
\hline Igarapé & 35.620 & 3,45 & Alta & 13 & 36,5 & 11 \\
\hline Brumadinho & 34.538 & 2,47 & Média & 5 & 14,5 & 13 \\
\hline
\end{tabular}

Fonte: Mapa da violência, 2013. (Dados trabalhados pela autora do artigo).

${ }^{26}$ Algumas metrópoles têm esses dados espacializados, mas o mesmo não ocorre com o conjunto dos municípios metropolitanos. Além disso, o acesso a esses dados não é público, como ocorre com o Datasus.
Janeiro, 55,2\% e, em Vitória, 25,8\%. Já em Belo Horizonte, cresceu 21,5\%. As taxas dos homicídios por 100 mil habitantes nessas capitais, em 
2011, foram: São Paulo 11,9, Rio de Janeiro 23,1, Belo Horizonte 40,3 e Vitória 56,6. A tabela 6 mostra a situação dos homicídios nos municípios da RMBH com mais de 20 mil habitantes.

Chama a atenção o fato de Esmeraldas apresentar a taxa mais alta de homicídios desse grupo, a posição 1 na última coluna. Trata-se de um município que vem evidenciando altas taxas de crescimento populacional $(7,6$, em 1991-2000 e 2,5, em 2000-2010) em virtude da expansão de uma ocupação de tipo periférico nas suas bordas, mais especificamente nos limites com Contagem e Ribeirão das $\mathrm{Ne}$ ves, ocupação marcada pelo nível mais baixo do Índice de Bem-Estar Urbano. Nos segundo, terceiro e quinto lugares, há municípios com Muito alta integração e com áreas de periferia com baixo bem-estar urbano (IBEU): Betim, Vespasiano e Ribeirão das Neves. Nas posições seguintes, quarto e sexto lugares, estão dois municípios com Alta integração: Juatuba e Sarzedo. Belo Horizonte ocupa a sétima posição. Outros três municípios chamam a atenção pelas taxas mais baixas de homicídios: Lagoa Santa (15), Brumadinho (13) e Nova Lima (12). Os três apresentam alta concentração de condomínios e poucas áreas de periferias. ${ }^{27}$

Esses dados tratam da incidência dos homicídios nos municípios, mas não da sua distri๑ buição interna. A importância da espacialização ণิ deve-se tanto ao fato de os homicídios apresentarem forte concentração espacial, quanto, para ซี os objetivos deste artigo, poder comparar sua o incidência nas diferentes áreas metropolitanas. Na falta desse dado para toda a RM, a análise $\rightarrow$ aqui apresentada vai se valer de um estudo so$\stackrel{0}{\circ}$ bre Belo Horizonte. O sociólogo Bráulio F. A. da \& Silva examinou, em sua tese, a distribuição esôे pacial dos homicídios em Belo Horizonte entre

caso de Sabará, na $14^{\mathrm{a}}$ posicão, e com uma periferia bastante precária no limite com Belo Horizonte precisa ser olhado com mais atenção, pois parece haver um problema - com os dados em função de variações muito bruscas de I um ano para outro: 0 homicídios em 2009, 21 em 2010 e 9 U em 2011, anos trabalhados pelo Mapa da Violência (2013) - para o cálculo da taxa, em 2011, apresentada na tabela. Esses dados também contrariam a trajetória anterior do município com taxas altas em $2008(30,8), 2007(39,4)$ e $2006(29,8)$ (Cf. ANDRADE e MARINHO, 2013).
1998 e 2006. O que ele observou foi a sua forte concentração em determinadas áreas ao longo do tempo. Nas palavras do autor, “... outro fator que nos chamou a atenção foi a forte estabilidade espacial de homicídios, isto é, nos nove anos considerados neste estudo, verifica-se que a violência característica de uma determinada área se repete ao longo do tempo, indicando uma forte previsibilidade com respeito aos locais violentos.” (Silva, 2012, p. 144). Essas áreas coincidem com as favelas localizadas nas áreas centrais e com as periferias situadas ao norte do município nas fronteiras com Sabará e Santa Luzia, ao sul com Ibirité e a oeste com Contagem.

Essas informações sobre a incidência dos homicídios são importantes, pois evidenciam outra face perversa das periferias que não estava presente, pelo menos, com tanta intensidade, nos anos da sua formação: a concentração da violência. Esse fenômeno foi responsável, inclusive, por um redirecionamento dos temas de pesquisa, tanto nas favelas (Valadares, 2005), quanto nas periferias (Feltran, 2011). E, se as melhorias (ainda que relativas) na infraestrutura minimizam a antiga representação da periferia como lugar de precariedade, já a violência atuou na direção contrária, ou seja, como um elemento a mais de estigmatização. O estigma é um atributo negativo que dificulta a aceitação social de uma pessoa. Pode ser, tanto um atributo físico, quanto social, e entre os mais importantes atributos sociais negativos está a pobreza (Goffman, 1975). Se a categoria periferias identifica os territórios da pobreza e é, portanto, estigmatizante, morar numa periferia (ou numa favela) violenta aumenta ainda mais o estigma e a suspeição. E, se a violência é seletiva (ainda que, muitas vezes, seja também arbitrária), o estigma territorial atinge todos os que moram no território estigmatizado.

\section{CONSIDERAÇÕES FINAIS}

Este texto colocou como problema entender as mudanças que se processaram nas 
últimas décadas nos espaços metropolitanos a partir de um conjunto de questões apontadas pela literatura e por uma relação entre elas e os dados do último Censo Demográfico. A RMBH foi tomada como caso para aprofundamento pelo fato de conhecê-la melhor e também devido à impossibilidade de analisar, de forma detida e individualizada, um conjunto tão diverso de regiões.

A primeira constatação é de que o espaço metropolitano continua muito desigual, ainda que a forma dessa desigualdade tenha se transformado. A antiga divisão entre centro e periferia é por demais limitada para se compreender um espaço que é muito mais fragmentado e complexo. Os municípios-polo continuam a exercer uma forte centralidade para o conjunto das RMs, mas seu baixo crescimento populacional é um reflexo de sua alta densidade, sua elitização, e da consequente perda de atratividade para outros centros, mais capazes de atrair investimentos como também população. Se os polos, em um determinado momento, deixaram de ser atrativos para a população de baixa renda, que se deslocou para os municípios periféricos, hoje eles perdem também população de média e de alta renda, assim como investimentos, para outros municípios. Esse processo levou à constituição de novas centralidades, algumas ainda vinculadas ao setor industrial, como as de Contagem e Betim, e outras ao setor de serviços qualificados e também para as moradias dos estratos de alta renda, como se verifica em Nova Lima.

As periferias passam por distintos processos de mudanças. A atração de grupos médios em função das melhorias na infraestrutura não foi possível de ser captada pelos dados aqui analisados, mas outros estudos já se dedicaram à sua análise (Caldeira, 2000, Lago, 2007 e Costa e Mendonça, 2011). Por outro lado, foi possível perceber, para a RMBH em especial, que algumas periferias antigas continuam ainda muito precárias quando comparadas com outros espaços e são hoje muito mais violentas. O caso de Ribeirão das Neves é em- blemático em relação a uma inércia das periferias. A precariedade habitacional, somada à falta de oferta de trabalho, fez com que o município continuasse a ser, cinco décadas depois, um município dormitório, pois $58,32 \%$ de sua população ocupada desloca-se cotidianamente para outros municípios, índice que, inclusive, cresceu em relação à década anterior, 55,42 em 2000 (Souza, 2014). Além disso, o município registrou uma taxa de 52 homicídios por 100 mil habitantes, a oitava pior taxa do estado de Minas Gerais. Verifica-se também a continuidade da periferização em espaços ainda mais afastados das áreas com oferta de serviços e trabalho, como pôde ser verificado no município de Esmeraldas.

Essas considerações remetem à compreensão da RMBH como marcada por processos de mudanças e de continuidades. De manutenção de uma centralidade no polo, acompanhada de processos de descentralização, de continuidade e expansão de novas periferias. Falar de permanência e inércia não é o mesmo que argumentar que as periferias não mudaram, mas que essas mudanças não foram suficientes para alterar sua posição em relação aos outros espaços da metrópole, de forma a diminuir as diferenças sociais e espaciais. Ou seja, as desigualdades espaciais continuam inscritas nos territórios metropolitanos, e as distâncias sociais permanecem, mesmo quando há proximidade física, como nos casos das favelas das áreas centrais e também dos condomínios nas periferias. E, se a percepção da insegurança atinge a todos, o mais letal dos crimes, o homicídio, concentra-se nas periferias.

Sobre uma nova configuração espacial, o que se constata, a partir do que foi aqui apresentado, é que os modelos duais não expressam a diversidade metropolitana brasileira. Por outro lado, cidades divididas é um conceito bastante alargado e, em tese, se adequaria a todas as cidades. A questão que merece ser mais bem analisada é como a divisão se inscreve no território. Algumas divisões expressam uma segmentação da sociedade por diferenças 
étnicas, profissionais ou culturais e não necessariamente a segregação. Um bairro étnico que reúne pessoas por questões de natureza sociocultural é muito diferente de um gueto. A segregação por questões etnicorraciais ou socioeconômicas implica acesso diferenciado aos bens urbanos, o que contribui para a continuidade das diferenças sociais. O que as divisões das metrópoles no Brasil indicam é a manutenção de uma forte segregação e a falta de integração entre os seus distintos espaços sociais. Ou seja, nesse aspecto fundamental da vida em sociedade, a configuração espacial das metrópoles aponta mais para a continuidade do que para a ruptura.

Recebido para publicação em 07 de setembro de 2014 Aceito em 13 de março de 2015

\section{REFERÊNCIAS}

ANDRADE, L. T. Segregação socioespacial e construção de identidades urbanas. In: MENDONÇA, J. G. de; GODINHO, M. H. de L. (Orgs.). População, espaço e gestão na metrópole. Belo Horizonte: PUC Minas, 2003, p. 59-72.

ANDRADE, L. T.; SOUZA, D. M. B. de L.; FREIRE, F. H.A. (Orgs.) Homicídios nas regiões metropolitanas. Rio de Janeiro: Letra Capital, 2013.

ANDRADE, L. T.; DINIZ, A. M. A. A reorganização espacial dos homicídios no Brasil e a tese da interiorização. Revista Brasileira de Estudos de População, v. 30, p. 171-91, 2013.

ANDRADE, L. T.; MARINHO, M. A. C. Organização social ๑ do território e violência letal na Região Metropolitana ㄱ. de Belo Horizonte: o balanço de uma década. In:

S. SOUZA, D. B.; FREIRE, F. H. M. de A. (Org.). Homicídios nas regióes metropolitanas. Rio de Janeiro: Letra Capital, 2013, p. 15-44.

ॠ ANDRADE, L. T.; MENDONCA, J. G. Explorando as œ consequências da segregação metropolitana em dois $\exists$ contextos socioespaciais. Cadernos Metrópole (PUCSP), - São Paulo, v. 23, p. 169-88, 2010.

BANERJEE-GUHA, S. Introduction: Transformative cities 2 in the new global order. In: ; (Ed.). Accumulation $§$ by dispossession. Transformative cities in the new global ¿ं order. New Delhi: Sage, 2010.

of BEAUREGARD, R. A. e HAILA, A. The unavoidable $\checkmark$ continuities of the city. In: MARCUSE, P. e VAN KEMPEN,

R. (Eds.) Globalizing cities: a new spatial order? London at and Cambridge: Blackwell Publishers, 2000.

BRASIL. Lei Complementar n. 14, de 8 de junho de 1973. क Disponível em: http://www.planalto.gov.br/ccivil 03/leis/ lcp/Lcp14.htm. Acesso em: 28 mar. 2014.

웡 BRASIL. Lei Complementar n. 20, de 1 de julho de 1974. D Disponível em: http://www.planalto.gov.br/ccivil 03/leis/ LCP/Lcp20.htm Acesso em: 28 mar. 2014.

岁 CALDEIRA, T. P.do R. Cidade de muros: crime, segregação e cidadania em São Paulo. São Paulo: Editora 34/Edusp, 2000 .

COSTA, H. S. de M. (Org.). Novas periferias metropolitanas. Belo Horizonte: C/Arte, 2006.

DINIZ, A. M. A e ANDRADE, L. T. Metropolização e hierarquização das relacões entre os municípios da RMBH. In: , MENDONÇA, J. G. E DINIZ, A. M. (Eds.). Belo Horizonte: Transformações na ordem urbana., Rio de Janeiro, Letra Capital, 2015.

DINIZ, C. C. e CAMPOLINA, B. A região metropolitana de São Paulo: reestruturação, re-espacialização e novas funções. Revista Eure, Santiago de Chile, v.1, n. 98, p. 2743, mayo 2007.

FARIA, C A. P. Explicando o inchaço da Região Metropolitana de Belo Horizonte. Revista do Observatório do Milênio de Belo Horizonte, Belo Horizonte, v. 3, p. 3659, 2012.

FELTRAN, G de S. Fronteiras de tensão: política e violência nas periferias de São Paulo. São Paulo: Editora Unesp, 2011.

FRÚGOLI JR., H.; CAVALCANTI, M. Territorialidades da(s) cracolândia(s) em São Paulo e no Rio de Janeiro. Anuário Antropológico, v. 2, p. 73-97, 2013.

. Centralidade em São Paulo: trajetórias, conflitos e negociações na metrópole. São Paulo: Cortez/Edusp/ Fapesp, 2000.

; SKLAIR, J. O bairro da Luz em São Paulo: questões antropológicas sobre o fenômeno da gentrification. Cuadernos de Antropología Social, v. 30, p. 119-36, 2009.

GOFFMAN, E. Estigma: notas sobre a manipulação da identidade deteriorada. Rio de Janeiro: LTC, 1975.

HARVEY, D. A condição pós-moderna: uma pesquisa sobre as origens da mudança cultural. São Paulo: Loyola, 1992.

IBGE. Instituto Brasileiro de Geografia e Estatística. Regiões de influência das cidades 2007. Rio de Janeiro: IBGE, 2008.

Instituto Brasileiro de Geografia e Estatística. Censo Demográfico de 2000. Rio de Janeiro: IBGE, 2001.

Instituto Brasileiro de Geografia e Estatística. Censo Demográfico de 2010. Rio de Janeiro: 2011.

JAMESON, F. Pós-modernismo. A lógica cultural do capitalismo tardio. São Paulo: Ática, 1996.

JAYME, J. G.; CHACHAM, A.; MORAIS, M. R. de. Mulheres da Zona Grande: negociando identidade, trabalho e território. Sexualidad, Salud y Sociedad, Rio de Janeiro, p. 138-63, 2013.

KING, A. D. Urbanism, colonialism and the world-economy. London: Routledge, 1990.

LAGO, L. C. Autogestão da moradia na superação da periferia urbana: conflitos e avanços. E-metropolis: Revista Eletrônica de Estudos Urbanos e Regionais, Rio de Janeiro, v. 5, p. 6-12, 2011.

LEITE, R. P. Contra-usos da cidade: lugares e espaço público na experiência urbana contemporânea. Campinas: Editora Unicamp/Editora UFS, 2004.

MARCUSE, P.; VAN KEMPEN, R. (Eds.) Globalizing cities: a new spatial order? London and Cambridge: Blackwell, 2000.

MARICATO, E. A producão capitalista da casa (e da cidade) no Brasil industrial. São Paulo: Alfa-Ômega, 1979.

MARQUES, EC. L.; REQUENA, C. O centro voltou a crescer? Trajetórias demográficas diversas e heterogeneidade na São Paulo dos anos 2000. Novos Estudos CEBRAP, p. 1736, 2013. 
MEDEIROS, R. Clínica e croni(cidade): impactos do uso/ abuso de crack na configuracão urbana e nos tratamentos da toxicomania. In: ; SAPORI, L. F. (Orgs.). Crack: um desafio social. Belo Horizonte: Ed. PUC Minas, 2010.

MENDONCA, J G.; COSTA, H S. M. Dinâmica imobiliária e a formação de um obscuro objeto de desejo: localização residencial e representação simbólica. In: . (Org.). Estado e capital imobiliário: convergências atuais na produção do espaço urbano brasileiro. Belo Horizonte: C/ Arte, 2011, p. 169-87.

MENDONÇA, J. G.; MARINHO, M. A.C. As transformações socioespaciais na Região Metropolitana de Belo Horizonte. In: ANDRADE, Luciana T. - DINIZ, Alexandre M. (Org.) Belo Horizonte: transformações na ordem urbana, Rio de Janeiro, Letra Capital, 2015.

MOLLENKOPF, J.; CASTELLS, M. (Eds.). Dual city: restructuring New York. New York: Sage, 1991.

NAZARIO, R. O.; ANDRADE, L. T. Da favela para o conjunto: a periferia no entorno do novo Centro Administrativo de Minas Gerais. Cadernos de Arquitetura e Urbanismo, Belo Horizonte, v. 1, p. 55-71, 2010.

OBSERVATÓRIO DAS METRÓPOLES. Níveis de integração dos municípios brasileiros em RMs, RIDES e AUS à dinâmica da metropolização. Rio de Janeiro, Observatório das Metrópoles, 2012. Disponível em: http:// observatoriodasmetropoles.net/download/relatorio integracao.pdf Acesso em: fevereiro de 2014.

OJIMA, $\mathrm{R}$ et alii. O estigma de morar longe da cidade: repensando o consenso sobre as "cidades-dormitório" no Brasil. Cadernos Metrópole, São Paulo, v. 12, n. 24, p. 395415, jul./dez. 2010

RIANI, J.L.R; RIOS-NETO, E.L.G. Análise espacial dos indicadores educacionais de Belo Horizonte e Região Metropolitana. Belo Horizonte: Fundação João Pinheiro, 2007. Texto para Discussão n. 31.

RIBEIRO, L C. de Q.; RIBEIRO, M. G. (Orgs.). IBEU - Índice de bem-estar urbano. Rio de Janeiro: Letra Capital, 2013.

(Org.). Hierarquização e identificação dos espaços urbanos. Série Conjuntura Urbana, v, 1 . Rio de Janeiro: Letra Capital: Observatório das Metrópoles, 2009. Disponível em: www.observatoriodasmetropoles.net. Acesso em: fevereiro de 2014.

Segregação residencial e políticas públicas: análise do espaço social da cidade na gestão do território. In: Saúde nos aglomerados urbanos: uma visão integrada. In: NETO, E. R.; BOGUS, C. M. (Orgs.). Brasília: Organização Pan-Americana da Saúde, 2003.

Segregação, acumulação urbana e poder: classes e desigualdades na metrópole do Rio de Janeiro. Cadernos IPPUR, Rio de Janeiro, 2002, p. 79-103.

ROBINSON, J. Global and world cities: a view from off the map. International Journal of Urban and Regional Research, v. 23, n. 6, p. 531-54, Sept. 2002,

RUBINO, S. Políticas de enobrecimento. In: FORTUNA C.; LEITE, R. P. (Org.). Plural de cidades: léxicos e culturas urbanas. Coimbra: Almedina, 2009, p. inicial e final.
SARAIVA, C. P. A periferia consolidada em São Paulo: categoria e realidade em construção. 2008, 162p. Dissertação (Mestrado em Planejamento Urbano) Universidade Federal do Rio do Janeiro, Instituto de Pesquisa e Planejamento Urbano e Regional. Rio de Janeiro.

SASSEN, S. As cidades na economia mundial. São Paulo: Studio Nobel, 1998.

SILVA, B. F. A. da. Desorganização, oportunidade e crime: uma análise "ecológica” dos homicídios em Belo Horizonte. 2012, 175p. Tese (Doutorado em Sociologia). Programa de Pós-graduação em Sociologia da Universidade Federal de Minas Gerais.

SIMÕES, R. e AMARAL, P. V. Interiorização e novas centralidades urbanas: uma visão prospectiva para o Brasil. Economia, Brasília (DF), v.12, n.3, p.553-79, set./ dez. 2011

SMITH, N. The new urban frontier. London \& New York: Routledge, 1996

SOARES, P R. R.; SCHNEIDER, L. P. Notas sobre a desconcentracão metropolitana no Rio Grande do Sul. Boletim Gaúcho de Geografia, v. 39, p. 113-28, 2012.

SOJA, E. W. Postmetropolis: critical studies of cities and regions. Malden, MA: Blackwell, 2000.

SOUZA, J. De. Organização social do território e mobilidade urbana. In: ANDRADE, L. T., MENDONCA, J. G. E DINIZ, A. M. (Eds.). Belo Horizonte: Transformações na ordem urbana. Rio de Janeiro, Letra Capital, 2015

TONUCCI FILHO, J. B. M. Cidade fractal - Transformações recentes na Região Metropolitana de Belo Horizonte. In: XII ENCONTRO NACIONAL ENANPUR, 2009, Florianópolis. Anais..., Florianópolis: ANPUR, 2009.

TORRES, H. da G.; MARQUES, E. C. Reflexões sobre a hiperperiferia: novas e velhas faces da pobreza no entorno municipal. Revista Brasileira de Estudos Urbanos e Regionais. n. 4, p. 49-70, maio 2001

VALLADARES, L. do P. A invenção da favela: do mito de origem à favela. Rio de Janeiro: Editora FGV, 2005.

VAN KEMPEN, R. Divided cities in the 21st century: challenging the importance of globalization. J Housing Built Environ, v. 22, p. 13-31, 2007

VIANNA, H. Manifesto da periferia. Revista Raiz, jan. 2007. Disponível em: ttp://revistaraiz. uol.com.br/portal/index.php?option =com content\&task $=$ view\&id $=220 \&$ Itemid $=181$. Acesso em março de 2014

VIEIRA, N C.; FELTRAN, G S. (Org.) Sobre periferias: novos conflitos no Brasil contemporâneo. Rio de Janeiro: Lamparina /FAPERJ, 2013.

WAISELFISZ, J J. Mapa da violência 2013: homicídios e juventude no Brasil. Brasília: OEI, 2012.

ZUKIN, S. Paisagens urbanas pós-modernas: mapeando cultura e poder. Revista do Patrimônio Artístico e Histórico Nacional, 24, p. 205-19, 1996. 


\section{METROPOLITAN SPACE IN BRAZIL: a new spatial order?}

\section{Luciana Teixeira de Andrade}

The goal of the text is to analyze the recent changes in the spatial order of Brazilian metropolitan areas and, particularly, the metropolitan area of Belo Horizonte. It begins with a dialogue with the international literature on the issue, and, after that, discusses the national debates. The empirical reference is a series of studies and indices built from the results of the Demographic Census of 2010. It shows the dual system downtown vs outskirts is too limited for comprehending the current sociospatial order or Brazilian metropoles. It identifies significant changes occurred over the last decades and calls attention to several continuums regarding socio-spatial inequalities.

KeYwords: Spatial order. Metropoles. Spatial inequalities. Downtown. Outskirts.

\section{L'ESPACE MÉTROPOLITAIN AU BRÉSIL: un nouvel ordre spatial?}

\section{Luciana Teixeira de Andrade}

L'objectif de ce texte est d'analyser les changements récents qui ont eu lieu dans l'ordre spatial des régions métropolitaines brésiliennes et en particulier dans la région métropolitaine de Belo Horizonte. Lanalyse commence par un dialogue avec les publications internationales sur ce thème pour en arriver ensuite aux débats nationaux. La référence empirique est constituée par toute une série d'études et d'indices construits sur la base des données du recensement de 2010. On y montre comment le double modèle centre versus périphérie est limité pour comprendre l'ordre sociospatial actuel des métropoles brésiliennes. On identifie aussi les changements importants qui ont eu lieu au cours des dernières décennies, mais on attire également l'attention sur la permanence de nombreuses inégalités socio-spatiales.

Mots-clés: Ordre spatial. Métropoles. Inégalités spatiales. Centres. Périphéries.

Luciana Teixeira de Andrade - Doutora em Sociologia. Professora do Departamento de Ciências Sociais e do Programa de Pós-graduação em Ciências Sociais da PUC Minas. Tem experiência acadêmica na área de Sociologia, com ênfase em Teoria Sociológica, e pesquisas realizadas sobre os seguintes temas: Belo Horizonte, Região Metropolitana, Condomínios Fechados, Espaços Públicos, Representações Urbanas e Criminalidade Urbana. Pesquisadora do CNPq, da Fapemig. Membro da equipe de pesquisadores do Observatório das Metrópoles. Consutora ad hoc da Capes e do CNPq. Publicações recentes: Circuito cultural Praça da liberdade: turismo e narrativas museológicas. Revista Iberoamericana de Turismo, v. 5, p. 5-17, 2015; Espaços públicos: interações, apropriações e conflitos. Sociologia (Porto), v. 29, p. 129-146, 2015; Intervenções urbanas mediadas pela cultura e os usos dos espaços públicos. Revista Ciências Sociais Unisinos, v. 50, p. 225-233, 2014. 